\title{
Para além do horizonte Ensino em Ciência Política no interior de Minas Gerais
}

\author{
Beyond the horizon \\ Political Science education in the interior of Minas Gerais \\ Además del horizonte \\ Enseñanza en Ciencia Política en el interior de Minas Gerais \\ (1) Rayza Sarmento ${ }^{1}$ \\ - Daniela Leandro Rezende ${ }^{1}$ \\ (1) Hilton Felippe dos Santos Júnior ${ }^{1}$
}

\begin{abstract}
Resumo: O artigo analisa como se organiza o ensino de Ciência Política no interior de Minas Gerais. Justifica-se pelo fato de que a compreensão de tal área disciplinar ainda é muito focada nas capitais brasileiras, especialmente onde há cursos de pósgraduação nos níveis de mestrado e doutorado. Interessa-nos avaliar as especificidades focadas no interior do País, especialmente em Minas Gerais, por esse ser um estado com maior concentração numérica de universidades federais no Brasil, além de possuir, para além da capital Belo Horizonte, departamentos e graduações em Ciências Sociais, que ofertam disciplinas e contam com corpo docente voltado para pesquisa e extensão específicas em Ciência Política. Empiricamente, a pesquisa se voltou para a coleta e a análise de dados sobre: a) oferta de disciplinas; b) construção de programas analíticos de disciplinas obrigatórias e optativas; e c) percursos de formação docente de professores/ as da área de Ciência Política.
\end{abstract}

Palavras-chave: Ensino. Ciência Política. Graduação. Minas Gerais.

Abstract: The article analyzes how Political Science teaching is organized in the interior of the state of Minas Gerais. It is justified by the fact that the understanding of such disciplinary area is still very focused on Brazilian capitals, especially where there are postgraduate courses, at masters and doctoral levels. We are interested in evaluating the specificities focused in the countryside, especially in Minas Gerais, because it is a state with greater numerical concentration of federal universities in Brazil, besides having, in addition to the capital Belo Horizonte, departments and undergraduate courses in Social Sciences, which offer courses and have faculty dedicated to specific research and extension courses in Political Science. Empirically, the investigation focused on the collection and analysis of data on: a) courses offered, b) syllabi of compulsory and elective subjects, and c) Political Science faculty training.

Keywords: Teaching. Political Science. Undergraduate course. Minas Gerais.

\footnotetext{
${ }^{1}$ Universidade Federal de Viçosa (UFV, Viçosa, MG, Brasil).

autores.dados_biográficos
}

Civitas, Porto Alegre, v. 19, n. 3, p. 605-624, set.-dez. 2019

Este artigo está licenciado sob forma de uma licença Creative Commons Atribuição 4.0 Internacional, que permite uso irrestrito, distribuição e reprodução em qualquer meio, desde que a publicação original seja corretamente citada. https://creativecommons.org/licenses/by/4.0/deed.pt_BR 
Resumen: El artículo analiza cómo se organiza la enseñanza de Ciencia Política en el interior de Minas Gerais. Se justifica por el hecho de que la comprensión de tal área disciplinaria todavía está muy enfocada en las capitales brasileñas, especialmente donde hay cursos de postgrado en los niveles de maestría y doctorado. Se interesa evaluar las especificidades enfocadas en el interior del país, especialmente en Minas Gerais, por ser un estado con mayor concentración numérica de universidades federales en Brasil, además de poseer, además de la capital Belo Horizonte, departamentos y graduaciones en Ciencias Sociales, que ofrecen disciplinas y cuentan con cuerpo docente orientado para investigación y extensión específicas en Ciencia Política. La investigación se volvió a la recolección y análisis de datos sobre: a) oferta de disciplinas, b) construcción de programas analíticos de disciplinas obligatorias y optativas y c) itinerarios de formación de docentes de Ciencia Política.

Palabras clave: Enseñanza. Ciencia Politica. Curso de grado. Minas Gerais.

\section{Introdução}

O objetivo deste artigo é analisar como se organiza o ensino de Ciência Política no interior de Minas Gerais, estado que concentra o maior número de universidades públicas federais do Brasil, cinco das quais oferecem atualmente cursos de graduação em Ciências Sociais. ${ }^{1}$

Estudos sobre a consolidação do campo da Ciência Política no Brasil destacam como centrais nesse processo as atividades relacionadas à pesquisa e à pós-graduação, tais como a delimitação de objeto de análise específico, o desenvolvimento de métodos adequados à análise de tais objetos e a emergência de publicações especializadas (Marenco, 2016; Avritzer, 2016). Ainda que tais critérios sejam pertinentes e permitam desenhar um quadro complexo desse processo, explicitam que pouca atenção tem sido dada às atividades desenvolvidas em nível de graduação e vários trabalhos têm se concentrado em entender a institucionalização da área a partir de dados estatísticos relativos aos programas de mestrado e doutorado, em especial, acerca da produção acadêmica (Leite e Codato, 2013). Isso pode estar relacionado ao pequeno número de cursos de graduação em Ciência Política e ao caráter especializado da formação, que ocorre, sobremaneira, no nível da pós-graduação. Ou, ainda, como apontam Bulcourf, Márquez e Cardozo (2014), pode dizer respeito à política da Ciência Política, o que, segundo os autores:

\footnotetext{
${ }^{1}$ Segundo os microdados do Censo da Educação Superior, em 2016 havia no Brasil 98 cursos presenciais de Ciências Sociais em atividade, nas modalidades bacharelado e licenciatura. A região de maior concentração era o Sudeste, com 31 cursos. Em Minas Gerais, o estado que apresenta o maior número de universidades federais no Brasil (onze), nove instituições entre capital, interior, públicas e privadas, ofertam graduação na área.
} 
[...] nos lleva a preguntarnos sobre los complejos mecanismos de construcción del prestigio, el otorgamiento del presupuesto de investigación y la construcción de la propia agenda, los sistemas de incentivos y las becas que son otorgadas bajo el nombre de la "neutralidad del campo del saber y el conocimiento" (Ravecca, 2010; 2014 apud Bulcourf, Márquez e Cardozo, 2014, p. 181).

Nesse sentido, argumentamos que tal compreensão dessa área disciplinar termina por reforçar desigualdades, uma vez que é muito focada nas capitais brasileiras, especialmente onde há cursos de pós-graduação stricto sensu em Ciência Política. Assim, além das desigualdades regionais características do sistema de pós-graduação brasileiro e, especificamente, da pós-graduação em Ciência Política, essas análises encerram também outra desigualdade, manifestada no eixo capital-interior. Em Minas Gerais, por exemplo, há apenas um curso de pós-graduação disciplinar em Ciência Política, ofertado pelo Departamento de Ciência Política da Universidade Federal de Minas Gerais (Capes, 2016). Os demais cursos nesse nível de ensino possuem caráter generalista, ou seja, são cursos strictu senso de Ciências Sociais, que podem ou não incluir linhas de pesquisa pertinentes à área de Ciência Política. No entanto, é importante destacar que o documento de área da Capes, que estabelece os critérios para criação e avaliação de cursos de pós-graduação em Ciência Política, sequer reconhece cursos de pós-graduação em Ciências Sociais como incluídos na área de Ciência Política. ${ }^{2}$

Esse quadro se torna ainda mais instigante se reconhecermos que, a despeito do já mencionado caráter especializado e concentrado da formação em Ciência Política, há profissionais da área atuando em todas as universidades públicas do estado de Minas Gerais. Esse quadro é reforçado a) pelo fato de Minas Gerais ser o estado que mais concentra universidades públicas no País; e b) por essa ser a principal trajetória de profissionais pós-graduados na área (Bulcourf, Márquez e Cardozo, 2014; Amorim Neto e Santos, 2005; 2015). Nesse sentido, cabe investigar como a formação especializada de tais atores se relaciona com a sua atuação e como as carreiras são orientadas diante desses cenários. Assim, perguntamos: como o ensino de graduação em Minas Gerais se articula com o processo mais amplo da consolidação do campo da Ciência Política no Brasil? Como características do campo, tais como o pluralismo temático (Avritzer, 2016) e a preocupação com o rigor metodológico

\footnotetext{
${ }^{2} \mathrm{O}$ documento da Capes aponta que "A área de Ciência Política e Relações Internacionais apresenta uma configuração crescentemente multidisciplinar, reunindo programas de Ciência Política, Relações Internacionais, Políticas Públicas, Defesa, Estudos Estratégicos” (Capes, 2016, p. 7).
} 
(Marenco, 2016) se manifestam nas atividades de ensino, pesquisa e extensão desenvolvidas nesse nível? Como essas questões se relacionam com o perfil profissional de docentes especialistas em Ciência Política?

Para responder a essas questões, a metodologia da pesquisa se baseou na construção de bancos de dados em que foram incluídos, inicialmente, os cursos de graduação em Ciências Sociais ofertados por universidades públicas federais e estaduais localizadas em Minas Gerais: Universidade Federal de Alfenas (Unifal), Universidade Federal de Juiz de Fora (UFJF), Universidade Federal de Uberlândia (UFU), Universidade Federal de Viçosa (UFV) e Universidade Estadual de Montes Claros (Unimontes).

A análise não incluiu a Universidade Federal de Minas Gerais UFMG, dadas as características específicas da oferta do curso de Ciências Sociais naquela universidade: as disciplinas de Ciência Política são ofertadas por um departamento específico de Ciência Política (DCP) e não de Ciências Sociais; o número de docentes do DCP/UFMG equivale a quase o total de docentes de Ciência Política das outras cinco universidades analisadas, consideradas em seu conjunto; o DCP/UFMG é tratado em todos os textos que contam a história da Ciência Política brasileira, o que reflete a sua centralidade e importância, mas termina por invisibilizar o ensino de graduação e o desenvolvimento da disciplina no interior. Esse quadro explicita, pois, a necessidade e a relevância do recorte proposto, considerando também que o foco aqui não é, pois, estabelecer uma comparação entre capital-interior.

Foram consideradas as seguintes variáveis: instituição, ano de criação do curso, modalidades dos cursos (bacharelado/licenciatura), número de disciplinas obrigatórias do curso, número de disciplinas obrigatórias da área de Ciência Política, nomes das disciplinas obrigatórias da área de Ciência Política (com seus programas analíticos), docentes com doutorado em Ciência Política, instituição/PPG em que o docente obteve doutoramento, ano de doutoramento.

Foram coletadas as ementas e os programas analíticos das disciplinas obrigatórias da área de Ciência Política, uma vez que essas, diferentemente das disciplinas optativas, voltam-se à formação básica ou mínima. A unidade de análise é, pois, curso de graduação-modalidade-universidade, já que foram incluídos cursos tanto de bacharelado, quanto de licenciatura.

As fontes de dados foram os sítios eletrônicos dos cursos analisados. No caso dos docentes, foram considerados aqueles e aquelas com doutorado reconhecido pela área de Ciência Política da Capes, excluindo os programas da subárea Relações Internacionais. A fonte de dados foi a Plataforma Lattes e os currículos dos profissionais atuantes no Estado, de onde foram extraídas 
também as suas inserções em projetos de pesquisa e extensão. A análise de dados envolveu tanto estatísticas descritivas quanto análise qualitativa, relativa ao conteúdo das disciplinas ofertadas. É preciso evidenciar o caráter ainda preliminar e descritivo da pesquisa realizada, seja pela indisponibilidade de certos dados, como será apresentado a seguir, bem como pela escassa literatura nacional, com dados empíricos, sobre o problema aqui delineado.

\section{Na graduação e no interior: a Ciência Política depois das capitais}

O marco inicial do desenvolvimento da Ciência Política no Brasil se deu com a criação de dois cursos de pós-graduação, em Minas Gerais e no Rio de Janeiro, na década de 1960. Nesse sentido, pode-se dizer que a história do campo profissional se confunde, em certa medida, com a história da pós-graduação em Ciência Política (Forjaz, 1997; Reis, 2016; Avritzer, 2016; Marenco, 2016), ou que a forma de falar sobre essa história reforça essa relação (Lessa, 2011). Segundo Amorim Neto e Santos (2015, p. 23), “[...] la dinámica de las carreras de posgrado, sin embargo, permite una medida más adecuada del comportamiento de las comunidades científicas", o que indica um entendimento de que é nesse nível que se intensifica a produção de conhecimento, que se consolida áreas de pesquisa e, por conseguinte, promove-se profissionalização.

Nesse sentido, Bulcourf, Márquez e Cardozo (2014) apontam que o processo de formação desse campo profissional no Brasil se distingue de outros países, como México e Argentina, em que houve primeiro a criação de cursos de graduação:

En el nivel de grado, Brasil cuenta con 14 licenciaturas en ciencia política. Por el contrario, en Argentina hay una gran cantidad de programas de grado que llegan a los 35 , de los cuales 15 se encuentran en la ciudad de Buenos Aires y sus alrededores. La explicación a esa diferencia es porque, en Brasil, la ciencia política es una orientación en los cursos en ciencias sociales que se continúa en la maestría. A diferencia de ello, en Argentina, la ciencia política nace con las licenciaturas y presenta un desarrollo tardío en el posgrado. México es el país con la mayor cantidad de programas de grado en ciencia política de toda América Latina, contando con 87 cursos (Gutiérrez et al., 2013 apud Bulcourf, Márquez e Cardozo, 2014, p. 168).

Como apontam os autores, "[...] esto tiene una especial incidencia en la conformación de la llamada identidad profesional, la manera en que se 
constituye su asociación de politólogos y el tipo de profesionalización del campo científico" (Bulcourf, Márquez e Cardozo, 2014, p.162). Dessa forma, como indicamos anteriormente, o principal destino de profissionais pós-graduados em Ciência Política no Brasil são as universidades brasileiras, havendo uma dinâmica de concentração institucional e regional, como apontam Amorim Neto e Santos (2015). Além disso, o caráter da associação profissional é predominantemente acadêmico.

Tal quadro se caracteriza, portanto, por uma série de assimetrias: o estabelecimento de uma dinâmica centro-periferia em dois níveis: o primeiro deles em que o centro são as universidades do Sudeste e o segundo em que o centro são as capitais; desigualdade de prestígio e de recursos entre o ensino de graduação e pós-graduação, em que

[...] las dificultades en las carreras de grado siguen siendo enormes -se han abierto las carreras, pero faltan profesores para dar cuenta de las disciplinas que se van a ofrecer. Además, los números relativos a la evasión de los alumnos no son animadores (Amorim Neto e Santos, 2015, p. 30).

Tais desigualdades explicitam um elemento da política da Ciência Política brasileira, que também pode ser notado pela quase ausência de referência a cursos de graduação, seja em Ciência Política ou em Ciências Sociais, na literatura sobre a formação e o desenvolvimento do campo no Brasil. Breve menção ao tema pode ser encontrada em Amorim Neto e Santos (2005, p. 107, grifo nosso), que apontam um caráter propedêutico desse nível de ensino, quando se pensa no campo de Ciência Política:

La mejoría de la educación de los alumnos de ciencias sociales es especialmente relevante para la ciencia politica de orientación más filosófica, cuyo principal obstáculo ha sido justamente la precaria formación y el pobre capital cultural de los alumnos que tienen diploma de graduado en esa gran área y que son la principal clientela de postgrado en politología. La graduación pasaría a ser, así, una etapa primordial para que los graduandos de ciencias sociales aprendiesen humanidades.

A pouca centralidade da graduação como âmbito de reflexão da Ciência Política brasileira também pode ser visualizada a partir do acompanhamento dos trabalhos apresentados na área temática de Ensino e Pesquisa em Ciência Política e Relações Internacionais dos Encontros da ABCP, especificamente 
naqueles disponíveis no site da associação e relativos aos eventos de $2012^{3}$, $2014^{4}$ e 2016.5

Dos trabalhos existentes, a graduação aparece como preocupação quando se trata dos bacharelados específicos em Ciência Política. O trabalho de Moraes et al. (2014) atesta a existência de 13 cursos desse tipo no País, em instituições de ensino públicas e privadas. O primeiro curso de graduação específico foi fundado na Universidade de Brasília (UnB), em 1989. Ao analisar os projetos políticos pedagógicos, Moraes et al. $(2014$, p. 4) afirma que

[...] o objetivo dos cursos dessa natureza é qualificar os egressos para o mercado da política, em especial a partir de três grandes áreas Eleições/Gestão e Estratégia de Campanhas Eleitorais; Administração Pública/Análise de Políticas Públicas e Gestão Governamental e Relações Políticas/Relações Governamentais e Institucionais.

Em paper anterior, Moraes e Azolin (2012) se preocupam com a outra face dessa relação, a saber, a perspectiva do mercado de trabalho para o/a graduado em Ciência Política, a partir de uma análise (pouco sistemática) de editais de consultoria e emprego. A despeito da pouca precisão sobre os dados analisados, entre os achados da pesquisa está a demanda de cientistas políticos para a formulação e a avaliação de políticas públicas como áreas de empregabilidade, especialmente, via consultoria. Segundo o estudo, "mesmo para o mercado de trabalho do cientista político fora da academia, o perfil exigido é acadêmico" (Moraes e Azolin, 2012, p. 12), com ênfase em pósgraduação stricto sensu nos processos de recrutamento e conhecimento em metodologia.

Outro par de textos apresentado nos eventos da $\mathrm{ABCP}$, e voltado à discussão do que é feito na graduação, se dedica aos debates metodológicos. O trabalho de Molin e Cigales (2014) demonstra preocupação com a formação de licenciandos em Ciências Sociais no tangente à aquisição de conhecimentos sobre Ciência Política. Os autores propõem a utilização de músicas para realizar o que chamam de "transposição de conceitos", especialmente acerca das noções de democracia, participação, representação política e cidadania.

\footnotetext{
${ }^{3}$ Disponível em: https://cienciapolitica.org.br/eventos/80-encontro-abcp/areas-tematicas/at-4/ ensino-e-pesquisa-ciencia. Acesso em: 10 abr. 2018.

${ }^{4}$ Disponível em: https://cienciapolitica.org.br/eventos/9o-encontro-abcp/areas-tematicas/at-4/ ensino-e-pesquisa-ciencia. Acesso em: 10 abr. 2018.

5 Disponível em: https://cienciapolitica.org.br/eventos/10o-encontro-abcp/areas-tematicas/at-4/ ensino-e-pesquisa-ciencia. Acesso em: 10 abr. 2018.
} 
Embora a proposta se mostre interessante, a análise de apenas quatro músicas escritas no contexto da ditadura militar brasileira, sem a apresentação ou construção de uma metodologia específica, não dá muitas pistas para pensar tal inserção como recurso frequente.

Já o estudo de Barberia et al. (2014) apresenta os desafios de ensinar métodos quantitativos na graduação, a partir do horizonte de pouca familiaridade ou contato dos graduandos com disciplinas como Matemática e Estatística. Os pesquisadores apresentam a experiência, ancorada em revisão bibliográfica, de um modelo de ensino baseado na realização de atividades, que consiste na resolução de problemas de forma individual ou em pares, ligados ao conteúdo das discussões do curso de Ciências Sociais.

Os autores defendem que o

[...] domínio de métodos quantitativos permite ao estudante se aprofundar nos debates contemporâneos, desenvolver posicionamento crítico em relação a "desenvolver habilidades importantes para a futura carreira profissional" (Barberia et al., 2014, p. 7).

Contudo, lembram que não há bibliografia sobre o ensino de métodos no Brasil nas Ciências Sociais, em especial na Ciência Política, para além da pós-graduação. Na revisão bibliográfica sobre o tema, atestam que no plano internacional, em especial nos Estados Unidos, pesquisas com essa preocupação aplicam surveys nos departamentos para entender a oferta de cursos de formação metodológica. Na experiência descrita com discentes da Universidade de São Paulo (USP), o conteúdo abrange itens como desenho de pesquisa e amostragem, mensuração, probabilidade, inferência estatística, teste de hipóteses, causalidade, correção, análise de variância e regressão.

Outro trabalho que busca pensar desafios no ensino na graduação é o de Nascimento e Santana (2012). Os autores focam na discussão sobre ontologia e epistemologia em Ciência Política, mas estabelecem um debate restrito com dois manuais em língua inglesa, que como sabemos não é tão acessível aos graduandos. Esses estudos apontam para a necessidade de observar como a Ciência Política é ensinada em nível de graduação para além dos cursos de bacharelado específicos. É no sentido de sanar essa lacuna, ainda de forma inicial, que apresentamos abaixo os resultados da pesquisa sobre as instituições públicas de Ensino Superior localizadas no interior de Minas Gerais onde há oferta de cursos de licenciatura e bacharelado em Ciências Sociais. 


\section{Estudo de caso: a Ciência Política nos cursos de Ciências Sociais em Minas Gerais}

Para este estudo, conforme já apontado, procuramos informações para todas as instituições públicas de Ensino Superior que oferecem graduação presencial em Ciências Sociais. Os dados finais, após uma pesquisa exploratória em novembro de 2017, foram coletados entre os meses de abril a junho de 2018, a partir dos sites das universidades, bem como por meio de troca de e-mails com os departamentos, quando as informações não estavam disponíveis ou não eram precisas.

O banco de dados sobre as instituições, inicialmente, foi construído com variáveis como: universidade, sigla, tipo (federal ou estadual), ano de criação do curso de Ciências Sociais, tipo de habilitação (bacharelado/licenciatura), total de disciplinas obrigatórias e optativas de Ciência Política, nome e ementas das disciplinas obrigatórias e optativas de Ciência Política. O banco de dados sobre os profissionais conta com informações acerca de nome do docente, currículo da Plataforma Lattes, número de docentes de Ciência Política por instituição, titulação docente, instituição de titulação, atuação prévia em IES privada e Ensino Básico, participação na pós-graduação, coordenação de projetos de pesquisa e extensão.

Foram encontradas seis instituições. Contudo, a análise se concentra em cinco delas, em função indisponibilidade de dados acerca da Universidade Estadual de Minas Gerais (UEMG)/Campus Barbacena. Assim, quatro são instituições federais e uma é estadual, a saber: Universidade Federal de Alfenas (Unifal), Universidade Federal de Juiz de Fora (UFJF), Universidade Federal de Uberlândia (UFU), Universidade Federal de Viçosa (UFV) e Universidade Estadual de Montes Claros (Unimontes). O curso de Ciências Sociais é ofertado nos campus sede em todas as universidades do corpus.

Todas as instituições oferecem os cursos nas duas modalidades, de licenciatura e bacharelado. A graduação mais antiga é a da UFJF, criada em 1947, seguida da Unimontes, em 1968. Os demais cursos foram fundados entre as décadas de 1990 e 2000, com os mais recentes na UFV e na Unifal (2009).

A pesquisa aponta para a média de 5,2 disciplinas obrigatórias de Ciência Política nos cursos analisados, com uma das universidades exigindo o máximo de 7 disciplinas (UFU). Nas obrigatórias, cujas ementas estão disponíveis no Quadro 1 (em Apêndice), vemos que, com exceção da UFJF, a sequência das disciplinas segue uma ordem cronológica. $\mathrm{Na}$ Unifal, a primeira disciplina tem caráter introdutório, voltada a conceitos fundamentais, como poder, estado, cidadania e representação. Na UFV, apesar do título, Introdução à Ciência 
Política, a disciplina se volta ao pensamento político pré-moderno. O período coberto pelas obrigatórias de Ciência Política vai desde a Antiguidade Clássica (UFV e Unifal) até a contemporaneidade (UFU, UFJF e Unifal). Na UFV, são privilegiados conteúdos associados à Teoria Política Moderna, presentes em duas das quatro disciplinas ofertadas, e na UFJF está presente apenas uma disciplina de teoria, Teoria Política Contemporânea.

A partir do Quadro 1, verificamos que há uma sobrerrepresentação de cursos voltados à teoria política, o que indica que o pluralismo característico do campo (Marenco, 2016; Avritzer, 2016) não se apresenta em três dos cursos analisados. A exceção é a UFJF, em que as disciplinas cobrem subáreas diversas, como teoria, instituições, políticas públicas e metodologia. Na UFU, igualmente há uma disciplina voltada aos estudos dos partidos políticos e sistemas eleitorais, que inclui também a discussão sobre movimentos sociais e micropolítica. A disciplina de Introdução à Ciência Política ofertada pela Unifal inclui a discussão sobre sistemas eleitorais, entre outros tópicos.

Se consideramos relevante que essa formação tenha caráter mais humanístico, como argumentam Amorim Neto e Santos (2005), essa ênfase seria adequada. Ademais, considerando, a partir de Calvino (2007), que clássicos são os textos que apontam questões fundamentais cuja centralidade se encontra sempre renovada, essa escolha poderia ser justificada. Entretanto, considerando que as disciplinas obrigatórias se referem aos conteúdos mínimos de Ciência Política ofertados a estudantes de Ciências Sociais, a ausência de conteúdos relacionados a outras subáreas pode ser problemática, além de apresentar um quadro enviesado e limitado do campo da Ciência Política. Uma das formas de superar essa limitação é inserir uma disciplina de caráter mais panorâmico, como a Introdução à Ciência Política, ofertada pela Unifal no primeiro período. Na Unimontes, conteúdos introdutórios também estão incluídos na disciplina Política I, que contempla ainda autores da Teoria Política Moderna.

A discussão sobre o Brasil está presente em quatro dos cinco cursos analisados, à exceção da Unifal. Entretanto, há diversidade nos temas e ênfases: na UFV, na disciplina Política Brasileira I, a discussão se volta à formação do Estado brasileiro, no período que se estende do Império à década de 1930; na UFU, são duas disciplinas obrigatórias, a primeira, Política Brasileira I, bastante próxima daquela ofertada pela UFV, ampliando-se até o ano de 1945 e a segunda, Política Brasileira II, que parte do pós-1945 e vai até a redemocratização. Na UFJF, a disciplina ofertada ganha o título de Pensamento Social Brasileiro II, não sendo delimitada temporalmente. Como informa a ementa, seu objetivo é "mostrar as possibilidades de leitura do Brasil 
a partir de teorias que pensam a nossa sociedade, quer através de uma chave histórica quer de uma chave analítica". ${ }^{6} \mathrm{Na}$ Unimontes, também não há um recorte temporal dos conteúdos e a ementa indica que será tratado o seguinte tema: "O processo político no Brasil a partir da relação estado/sociedade: vínculos e mediações entre a formação dos atores políticos e os processos de construção institucional". 7

A Figura 1, a seguir, é uma nuvem de palavras, construída a partir da recorrência dos termos nas ementas das disciplinas obrigatórias das cinco instituições.

Figura 1 - Termos mais recorrentes nas ementas das disciplinas obrigatórias de Ciência Política nos cursos de Ciências Sociais da UFJF, UFV, UFU,

Unifal e Unimontes

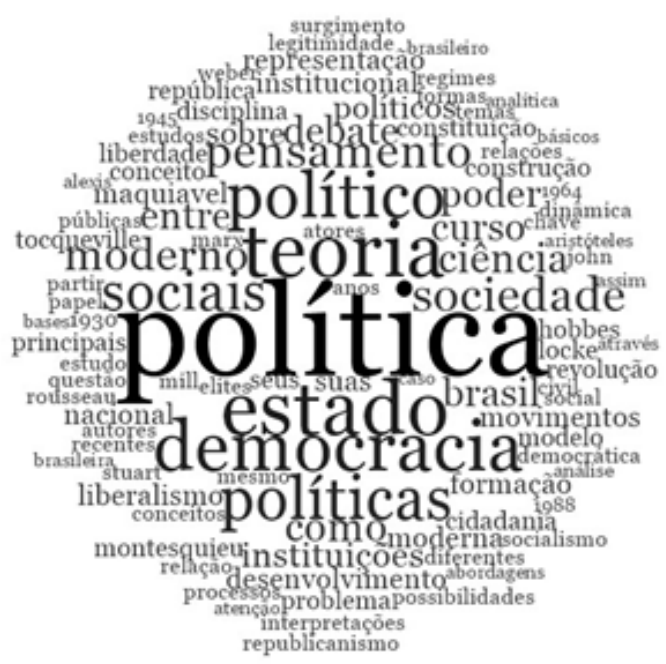

Fonte: Elaborado pelas autoras com dados da pesquisa.

Esta figura reforça o exposto anteriormente, qual seja, a ênfase em teoria política, e a pequena presença de termos relacionados às demais subáreas, como instituições e representação, apenas para citar um exemplo. Apenas a UFJF oferece uma disciplina de caráter metodológico voltada especificamente à Ciência Política, que inclui reflexão sobre uma diversidade de estratégias, como estudos comparados, teoria formal e análise computacional.

\footnotetext{
${ }^{6}$ Graduação em Ciências Sociais, UFJF, Disciplina: Pensamento Social Brasileiro II.

7 Graduação em Ciências Sociais, Unimontes, 2018.
} 
Não pretendemos aqui fazer uma discussão normativa a respeito de que conteúdos devem ser ensinados, mas apenas apontar a distância entre o caráter plural do campo de Ciência Política, quando observado a partir da pesquisa e da pós-graduação, e a sobrerrepresentação da área de Teoria Política (ou Filosofia Política ou História do Pensamento Político) nas disciplinas obrigatórias de Ciência Política ofertadas nos cursos de Ciências Sociais analisados. Essa distância pode estar relacionada aos diferentes objetivos desses níveis de ensino e ao caráter mais generalista da graduação em Ciências Sociais, quando comparado à pós-graduação em Ciência Política, de caráter, portanto, disciplinar.

Além disso, a metodologia adotada nessa fase da pesquisa limita o olhar para aspectos mais formais e estáveis dos cursos de Ciências Sociais, como as ementas e referências bibliográficas disponíveis nos projetos pedagógicos dos cursos. Há a possibilidade, portanto, que as ênfases apontadas não estejam presentes, ou sejam afetadas por características de docentes responsáveis pelas disciplinas, tais como formação e experiência profissional, além de poder haver mudanças apresentadas em programas de cursos, de caráter semestral ou anual e outras relacionadas ao recurso a diferentes metodologias de ensino e aprendizagem. A fim de mitigar tal lacuna, um futuro desdobramento da pesquisa é analisar detidamente as referências bibliográficas informadas como fundamentais nos projetos políticos pedagógicos dos cursos e nos programas de disciplina.

Além de mapear a composição curricular, observamos o perfil dos e das docentes efetivos dos cursos. Somando as cinco universidades, temos um total de 21 docentes que atuam nas disciplinas da área de Ciência Política, sendo 14 do gênero masculino e 7 do gênero feminino. Esse é um dado que, em pesquisas comparativas com outros estados e outras áreas do conhecimento, poderia fornecer um quadro importante acerca de desigualdade no ingresso de docentes no tangente ao gênero. Na Unifal, todos os quatro docentes são do gênero masculino. Na UFJF, dos oito docentes, há seis professores e duas professoras. Na UFU, dos três docentes, dois são do gênero masculino. UFV e Unimontes apresentam o mesmo número de docentes na área, com mesma distribuição, duas professoras e um professor.

Sobre a formação, há docentes com doutorado em Ciência Política (CP) na Unifal, UFJF e UFV. Tem-se o total de 12 docentes com doutorado em CP nas três IES, sendo oito do gênero masculino e quatro do gênero feminino. Acerca da titulação, os dados mostram que a Unimontes e a UFU não possuem professores doutores com titulação máxima em Ciência Política. Na estadual, são dois professores com doutoramento em 
área afim $^{8}$ e um docente com o mestrado concluído em CP. Na federal de Uberlândia, são três mestres em Ciência Política. A UFV, por sua vez, é a única em que todos os docentes da área têm doutorado em CP. Na Unifal, são três docentes com doutorado e um com mestrado em CP. Na UFJF, dos oito docentes, seis têm doutorado em $\mathrm{CP}$, um com mestrado na área e um docente com doutorado em área relacionada. Notamos que embora duas universidades não apresentem doutores na área, há uma grande presença de mestres em CP. Uma explicação possível é acerca da tendência, em anos anteriores, de os concursos públicos para universidades do interior abrirem vagas para classes como auxiliar e assistente, que não requerem o doutorado.

Dos 12 doutores em CP das cinco IES, seis obtiveram o seu título de doutorado pela UFMG (50\%), quatro pelo Iuperj $(33,33 \%)$ e dois pela Uerj (16,67\%). Esse dado revela uma predominância das instituições tidas como fundadoras do campo no Brasil, padrão que aponta tanto para a força desses programas de pós-graduação ao longo do tempo e ainda para certa concentração de ex-discentes de doutorado da região Sudeste.

Tais achados convergem com o apresentado em Amorim Neto e Santos (2015), ao revisarem pesquisa acerca do perfil dos cientistas políticos.

Oliveira y Nicolau también presentan un perfil de los politólogos brasileños: $68 \%$ son hombres; $74 \%$ son profesores y $93 \%$ trabajan en instituciones brasileñas. Después, identifican las instituciones a las que pertenecen: seis de ellas concentran el 55\% de los autores (USP, Iuperj/Iesp, UFMG, Universidad de Brasilia [UnB], Centro Brasileiro de Análise e Planejamento [Cebrap] y Universidad de Campinas [Unicamp]). Además de la concentración institucional, también hay concentración regional: cerca de tres cuartos de los autores de los trabajos pertenecen a instituciones localizadas en la región Sudeste (Amorim Neto e Santos, 2015, p. 24).

A respeito da atuação na pós-graduação, de acordo com os currículos disponíveis na Plataforma Lattes, verificou-se que 11 dos 21 docentes são integrantes de programas de mestrado e/ou doutorado. Todos os docentes da UFU atuam em pós-graduação. Nas demais universidades, mais da metade do corpo docente de Ciência Política está na pós-graduação.

Os currículos pesquisados atestam uma inserção maior dos docentes em pesquisa do que em extensão, conforme a Tabela 1, a seguir. A coleta considerou os projetos em que os docentes se autoassinalavam no Lattes como coordenadores.

\footnotetext{
${ }^{8}$ Como área relacionada, consideramos os PPGs em Sociologia Política e Relações Internacionais.
} 
Tabela 1 - Docentes, projetos de pesquisa e extensão por IES

\begin{tabular}{lccc}
\hline IES & No de docentes & $\begin{array}{c}\text { No de projetos } \\
\text { de pesquisa }\end{array}$ & $\begin{array}{c}\text { No projetos } \\
\text { de extensão }\end{array}$ \\
\hline UFJF & 8 & 13 & 4 \\
UFU & 3 & 4 & 0 \\
UFV & 3 & 6 & 2 \\
Unifal & 4 & 2 & 0 \\
Unimontes & 3 & 7 & 1 \\
\hline
\end{tabular}

Fonte: Elaborado pelas autoras.

Sobre a atuação profissional anterior ao ingresso como servidor público federal, dos docentes que possuem doutorado em CP, dez atuaram previamente em uma IES privada, contra dois que não tiveram essa trajetória. Quando observados todos os docentes com mestrado e doutorado, por instituição, em todas há sempre uma porcentagem maior que $50 \%$ com vínculo anterior a faculdades particulares, sendo que na UFU e na UFV todos e todas as professoras tiveram tal experiência prévia. Esse é um padrão interessante para entender a formação profissional, dado que indica um foco na carreira acadêmica.

Tal dado se articula com outro achado acerca da atuação na educação básica. Dos doze doutores em Ciência Política, apenas dois trabalharam anteriormente no Ensino Básico. Nenhum docente da UFU e Unimontes atuou em tal nível de ensino. Nas demais IES, apenas um professor ou professora apresenta tal trajetória. É possível que esse quadro se dê em função de os professores, em sua maioria, serem bacharéis e não licenciados em Ciências Sociais ou, ainda, sejam oriundos de cursos de graduação não voltados diretamente à área educacional. Essa se apresenta como uma futura linha de investigação. É preciso ressaltar, ainda assim, que o documento de área da Capes (2016, p. 8-9) assinala que,

[...] ainda que não possua disciplina específica na grade disciplinar do ensino médio, as áreas de Ciência Política e Relações Internacionais podem desenvolver ações de impacto na formação de professores para o ensino médio, a partir do reforço de conteúdos em áreas como formação e estrutura das instituições políticas brasileiras, relações intergovernamentais, políticas públicas, relações internacionais.

A não experiência prévia de ensino dos docentes em tal nível de educação pode vir a dificultar essa relação. O referido documento cita também o 
Programa Institucional de Bolsa de Iniciação à Docência (Pibid) e "incentiva a participação pelos Programas em propostas institucionais desenvolvidas pelas Universidades" (Capes, 2016, p. 10).

\section{Considerações finais}

Este trabalho buscou construir, ainda que de forma preliminar, um retrato sobre o ensino da Ciência Política no interior de Minas Gerais, observando centralmente cinco universidades públicas que oferecem graduação presencial em Ciências Sociais. Conforme discutimos ao longo do texto, a configuração da Ciência Política enquanto disciplina no interior difere da discussão mais canônica sobre a formação da área, que enfatiza o nível de pós-graduação, em especial, focada nos debates do pluralismo metodológico. A formação dos docentes também é diversa, incluindo um número de professores que não possuem doutorado e com pós-graduação em áreas afins ou mesmo em outros campos. Mais do que apontar conclusões do estudo, ainda em andamento, gostaríamos de pontuar entraves e possibilidades futuras, que poderiam contribuir para a consolidação de uma agenda de pesquisa sobre o tema.

$\mathrm{O}$ maior entrave encontrado diz respeito à ausência de literatura nacional mais robusta sobre o ensino na graduação. As análises, conforme apontamos na revisão de literatura, ainda se concentram no nível de pós-graduação. Embora todas as justificativas para esse fato sejam plausíveis, em especial àquelas ligadas à autonomização e à consolidação da Ciência Política como um campo, a não observação sistemática sobre a porta de entrada gera um desconhecimento sobre como autores, escolas e teorias são apresentadas ainda no Ensino Superior. Essa não relação se expressa na própria construção dos ementários dos cursos de graduação, focados muito mais em Teoria Política do que nas subáreas, essas em crescente especialização.

Um segundo entrave mais operacional se liga à pouca atualização dos dados tanto nos sites das universidades e departamentos quanto dos Lattes de vários docentes. A pesquisa sobre ensino depende, fundamentalmente, dessas fontes de dados. Entretanto, os problemas na execução se colocam menores do que as provocativas questões ainda em aberto. A pesquisa caminhará para a análise detida das bibliografias das disciplinas de Ciência Política. Conhecer autores, temas e escolas é fundamental para a compreensão de como o campo é apresentado aos discentes de graduação. Investigaremos quais as similaridades e dissonâncias entre as instituições, como as subáreas da CP se fazem presentes e como os debates candentes, como a presença de mulheres autoras e a necessidade de expressão mais igualitária de gênero nas bibliografias, se colocam. 
A trajetória prévia dos docentes também enseja questões. Buscaremos entender se eles e elas vêm majoritariamente da graduação em Ciências Sociais ou de outras áreas, quais são seus campos de pesquisa, como se alinham às instituições mais centrais, em especial, as de formação. Além disso, outra possibilidade é analisar o perfil e a atuação de docentes pós-graduados em Ciência Política, que atuam em universidades que não ofertam cursos de Ciências Sociais.

Esperamos que a pesquisa possa contribuir para a compreensão mais matizada da área de Ciência Política na graduação, em especial na formação obrigatória dos discentes e no perfil e na atuação docente em pesquisa e extensão para além da capital mineira. Finalmente, apontamos a necessidade de expansão dessa análise para outros estados, a fim de que possamos construir um retrato robusto de como a área se desdobra na formação e na atuação profissional de cientistas sociais e políticos indo além das estatísticas sobre pesquisa e pós-graduação.

\section{Referências}

AMORIM NETO, Octavio; SANTOS, Fabiano. La ciencia política en Brasil: el desafío de la expansión. Revista de Ciencia Política, Santiago, v. 25, n. 1, p. 101-110, 2005. https://doi.org/10.4067/s0718-090x2005000100007

AMORIM NETO, Octavio; SANTOS, Fabiano. La Ciencia Política en Brasil en la última década: la nacionalización y la lenta superación del paroquialismo. Revista de Ciencia Politica, Santiago, v. 35, n. 1, p. 19-31, 2015. https://doi.org/10.4067/s0718090x2015000100002

AVRITZER, Leonardo. O papel do pluralismo na formação e consolidação da ciência política no Brasil. In: AVRITZER, Leonardo; MILANI, Carlos; BRAGA, Maria do Socorro (org.). A ciência política no Brasil: 1960-2015. Rio de Janeiro: FGV, 2016. p. 165-186. https://doi.org/10.1590/0103-335220192908

BARBERIA, Lorena Guadalupe et al. Novas experiências com o ensino de métodos em Ciência Política. In: Encontro da ABCP-AT Ensino e Pesquisa em Ciência Política e Relações Internacionais, 9, 2014, Brasília. Anais [...]. Brasília: [s. n.], 2014. https:// doi.org/10.17951/al.2014.1.0.155

BUlCOURF, Pablo; MÁRQUEZ, Enrique Gutiérrez; CARDOZO, Nelson. El desarrollo de la Ciencia Política en Argentina, Brasil y México: construyendo una mirada comparada. Anuario Latinoamericano: Ciencias Políticas y Relaciones Internacionales, [s.l.], v. 1, p. 155-184, 2014.

CALVINO, Italo. Por que ler os clássicos. São Paulo: Companhia das Letras, 2007. 
CAPES. Documento de área: área 39: Ciência Política e Relações Internacionais. Brasília: CAPES, 2016.

FORJAZ, Maria Cecília Spina. A emergência da ciência política no Brasil: aspectos institucionais. Revista Brasileira de Ciências Sociais, São Paulo, v. 12, n. 35, 1997. https://doi.org/10.1590/s0102-69091997000300007

LEITE, Fernando; CODATO, Adriano. Autonomização e institucionalização da Ciência Política brasileira: o papel do sistema Qualis-Capes. Agenda Política, São Paulo, v. 1, n. 1, p. 1-21, 2013.

LESSA, Renato. O campo da Ciência Política no Brasil: uma aproximação construtivista. Revista Estudos Hum(e)anos, [s. l.], n. 2, p. 3-31, 2011.

MARENCO, André. Cinco décadas de ciência política no Brasil: institucionalização e pluralismo. In: AVRITZER, Leonardo; MILANI, Carlos; BRAGA, Maria do Socorro (org.). A ciência política no Brasil: 1960-2015. Rio de Janeiro: FGV, 2016. p. 141-164. https://doi.org/10.1590/0103-335220192908

MOLIN, Naiara; CIGALES, Marcelo. Trabalhando a ciência política em sala de aula: recursos didáticos e metodológicos. In: Encontro da ABCP-AT Ensino e Pesquisa em Ciência Política e Relações Internacionais, 9, 2014, Brasília. Anais [...]. Brasília: [s. n.], 2014. https://doi.org/10.4025/imagenseduc.v5i3.26492

MORAES, Luiz Fernando et al. Os cursos de bacharelado em Ciência Política no Brasil: refletindo sobre a questão da docência. In: Encontro da ABCP-AT Ensino e Pesquisa em Ciência Política e Relações Internacionais, 9, 2014, Brasília. Anais [...]. Brasília: [s. n.], 2014. https://doi.org/10.33167/2184-2078.rpcp2018.9/pp.111-137

MORAES, Luiz Fernando; AZOLIN, Audren. Os cursos de bacharelado em ciência política no Brasil: a perspectiva do mercado de trabalho. In: Encontro da ABCP-AT Ensino e Pesquisa em Ciência Política e Relações Internacionais, 8, 2012, Gramado. Anais [...]. Gramado: [s. n.], 2012. https://doi.org/10.29327/13455

NASCIMENTO, Emerson; SANTANA, Lucian. Com que teoria? Aprendendo e ensinando sobre ontologia e epistemologia no estudo da Ciência Política. In: Encontro da ABCP-AT Ensino e Pesquisa em Ciência Política e Relações Internacionais, 8, 2012, Gramado. Anais [...]. Gramado: [s. n.], 2012. https://doi. org/10.7476/9788575415092.0006

REIS, Fabio W. Huis clos no Chile e ciência política no Brasil. In: AVRITZER, Leonardo; MILANI, Carlos; BRAGA, Maria do Socorro (org.). A ciência política no Brasil: 1960-2015. Rio de Janeiro: FGV, 2016. p. 13-60. https://doi.org/10.1590/0103335220192908 


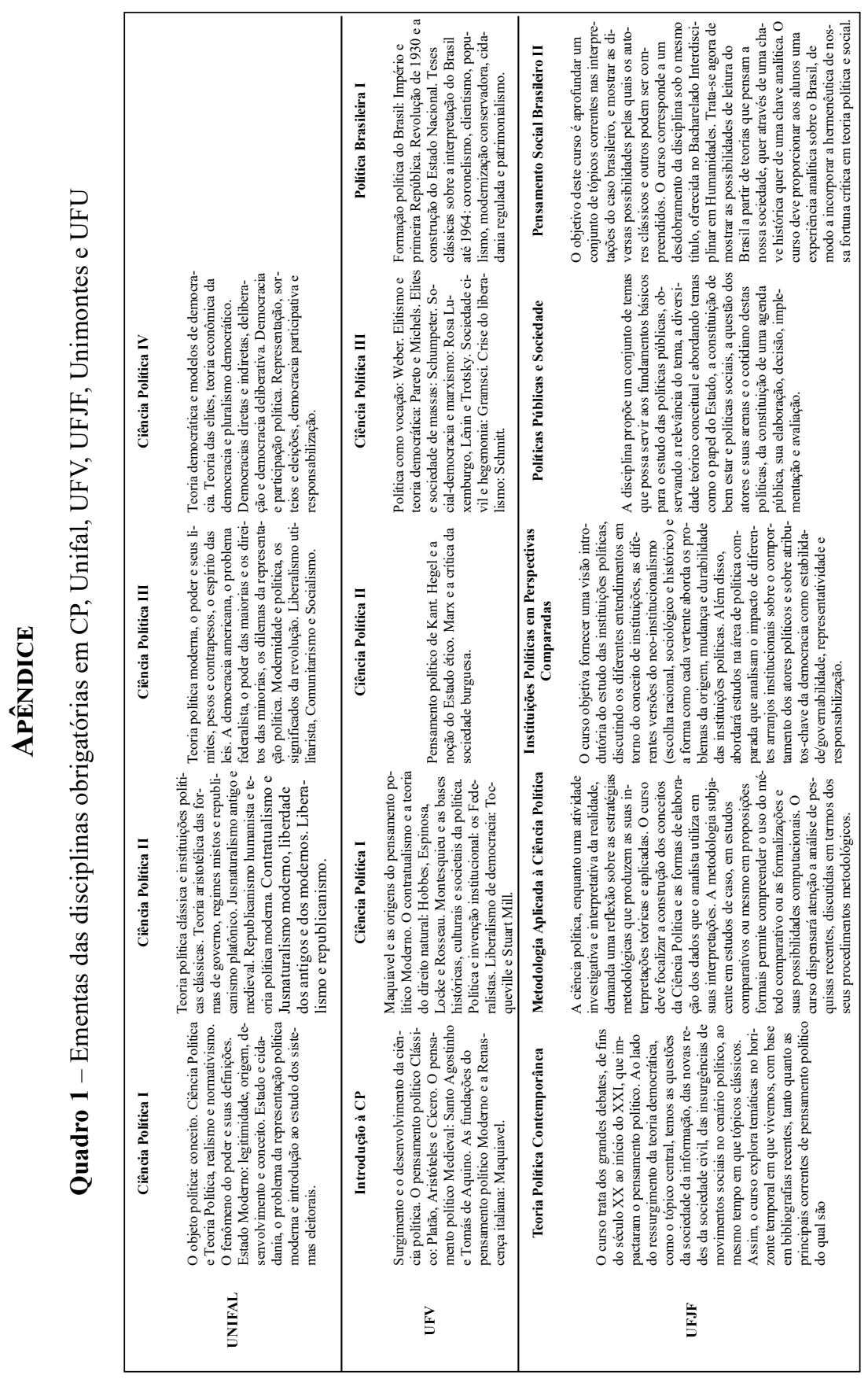




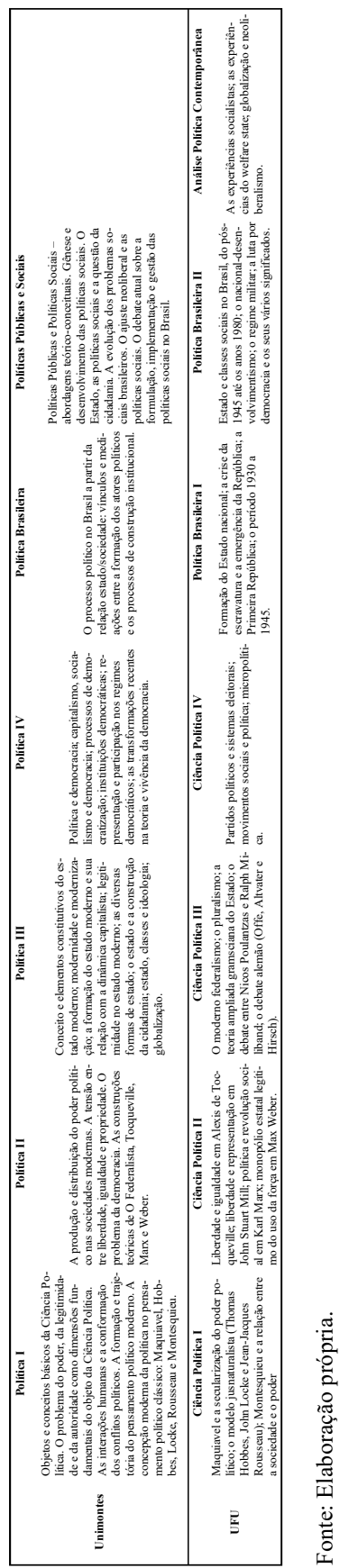


Recebido em: 27/2/2019.

Aprovado em: 27/5/2019.

Publicado em: 15/12/2019.

Autora correspondente:

Rayza Sarmento

Universidade Federal de Viçosa

Gabinete 401 - Departamento de Ciências Sociais

Campus Universitário - Prédio do CCH II

Av. Peter Henry Rolfs, $\mathrm{s} / \mathrm{n}$

36570-900, Viçosa, MG, Brasil

RAYZA SARMENTO <yzasarmento@gmail.com>

Doutora em Ciência Política pela Universidade Federal de Minas Gerais (Belo Horizonte, MG, Brasil). Professora Adjunta do Departamento de Ciências Sociais da Universidade Federal de Viçosa (UFV, MG, Brasil).

Orcid: http://orcid.org/0000-0002-9817-7941

DANIELA LEANDRo REZENDE < danielarezende@tutanota.com>

Doutora em Ciência Política pela Universidade Federal de Minas Gerais (Belo Horizonte, MG, Brasil). Professora Adjunta do Departamento de Ciências Sociais da Universidade Federal de Viçosa (UFV, MG, Brasil).

Orcid: http://orcid.org/0000-0003-0461-7940

HiLton FeliPPE dos SANTOS JÚNIOR < hiltonfelippejr@gmail.com>

Graduando da Universidade Federal de Viçosa (UFV, MG, Brasil).

Orcid: http://orcid.org/0000-0002-1886-6369 